\title{
CONCEPTUAL METAPHORS OF 'ECONOMIC CRISIS' IN ENGLISH: A HISTORICAL COGNITIVE PERSPECTIVE
}

\author{
Iryna Shevchenko* \\ V.N. Karazin Kharkiv National University
}

This article explores the role of metaphor in the conceptualization of economic crisis in English in terms of the sociohistorical - cognitive linguistic interface. On the material of economic mass-media discourse of the $19^{\text {th }}$ century "long depression", the $20^{\text {th }}$ century Great Depression and the $21^{\text {st }}$ century Global Economic Crisis it reveals the concept historical variation and defines the vector of its development. It also develops the methodology of historical cognitive analysis and proves that being a part of human social-cultural practice cognition is of historical nature. I claim that in historical perspective conceptual metaphors vary in their source domains as the result of transformations of the concept structure. The vector of diachronic change of conceptual metaphors of ECONOMIC CRISIS corresponds to cladogenesis, which is the process of evolutionary splitting based on branching.

Keywords: concept, diachronic change, historical cognitive linguistics, conceptual metaphor, cladogenesis.

\section{Introduction}

In this paper, I would like to present the historical vector of cognitive linguistics, and to illustrate this paradigm I chose the historical variation of conceptual metaphors of ECONOMIC CRISIS from the $19^{\text {th }}$ to the $21^{\text {st }}$ centuries. More specifically, I aim to study linguistic means representing this concept in the economic and political mass-media discourse of two historical periods: 1929-33 and 2007-10 with a brief mention of the 18731896 "long depression" to reveal their synchronic and diachronic distinctions and define the vector of their variation.

*iryna.shevchenko@karazin.ua

This work is licensed under a Creative Commons Attribution-NonCommercial 4.0 International License.
Received: 14.12 .2020

Revised: 20.02 .2021

Accepted: 06.04.2021

(C) The Author(s) 2021 
In modern societies, crisis has become a characteristic feature and a focus of social, political, and economic researches within the Theory of Crisis. In economic and political studies, crisis is treated as an integral part of the classical model of economic cycle comprising 4 stages: rise/expansion - decline/crisis - recession - recovery (Haberler, 2001).

Until recently, the linguistic analysis of the metaphoric conceptualization of economic crisis in various languages (Browse, 2013) has mostly been synchronous. It has revealed that among related conceptual metaphors in English, Serbian and Romanian, the most productive are ECONOMICS IS A LIVING BEING, ECONOMICS IS A HOUSE, etc. (Silaški et al. 2012). Metaphors of ECONOMIC CRISIS have also been described through ontological opposition dream::nightmare, justice::chaos, etc. (Stronach et al., 2014).

In this study, I apply a historical-cognitive framework to the study of conceptual metaphors of ECONOMIC CRISIS in English. As Geeraerts, Kristiansen, and Peirsman (2010) put it, the basic architecture of language involves socioculturally situated or embedded cognition. Such cognition changes with the historical transformation of culture and society. I aim to prove that metaphors of ECONOMIC CRISIS reveal historical variation together with the varied socio-cultural parameters and language development.

For this aim, I will begin with the analysis of a methodological basis, the algorithm and material of study, then describe the data from each stage of research and the preliminary results, and finally formulate some conclusions and draw the perspectives for analysis.

\section{Methodology and material}

The methodology of this analysis of conceptual metaphors of ECONOMIC CRISIS in the English mass-media discourse of the last few centuries is a complex of conceptual metaphor theorizing and historical cognitive perspective.

There are many theories of conceptual metaphor: Lakoff and Johnson's views (1980/2003), Kövecses' levels of metaphor (2017), which interpret target concepts in terms of source concepts. The theory of conceptual integration or blending (Fauconnier \&Turner, 2003) and embodiment 
hypothesis suggest that people comprehend abstract concepts via concrete ones. As Fauconnier (2006, p. 10) puts it, "cognitive linguistics goes beyond the visible structure of language and investigates the considerably more complex backstage operations of cognition that create grammar, conceptualization, discourse, and thought itself". Conceptual metaphor is understood as a result of cross-mapping of elements from a source domain to a target domain with a set of ontological correspondences (Fauconnier, 2006, p.7). This theory of conceptual mapping adds to the standard source and target domains and explains domain cross-mapping as the process of "input spaces $_{1,2}$ " being cross-mapped into "generic" space possessing elements common to both input spaces, and finally into a "blended" space, which unites elements from both input spaces into a new conceptual structure of its own.

Proceeding from this theoretical background, I take an evolutionary viewpoint on metaphoric conceptualization, which treats intellect as the product of creative evolution (Bergson, 1911/2008). Recently, historical vector is becoming more and more popular in cognitive linguistics. In figurative language, Barcelona (2006, p. 21-39) claims that metonymy motivates the semantic evolution of lexical units. In grammar and semantics, Guarddon-Anelo (2006) develops a cognitive approach to the diachronic study of spatial prepositions. In lexical semantics, Robinson (2010, p. 85-109) makes insights into historical cognitive semantic variation; while Oncins-Martínez (2006, p. 205-224) analyses the role of conceptual metaphor in the categorization of sexual matters as one of the most metaphorized and taboo target domains in Old English. In crosscultural perspective, Pérez (2006, p.181-193) makes a diachronic cognitive cross-linguistic study of body metaphors in Germanic and Romance languages, which supports the idea of embodiment claimed by the cognitive linguistics.

I focus on historical transformations of conceptual metaphors of ECONOMIC CRISIS in terms of the sociocultural - cognitive - linguistic interface. I argue that "being a part of human social and cultural practice, cognition is of historical nature" (Shevchenko, 2015, p. 64) since culture is a historically changing system. In this regard a cognitive linguistic research requires diachronic approach as both language and culture can manifest their dynamics and variability through time only in socio-historical facts 
(Shevchenko, 2015; Winters, 2010).

This paper is part of an ongoing project that aims to elaborate the tendencies of historical development of different concepts of culture, economics, and politics. The data for this study are 900 examples of conceptual metaphors of ECONOMIC CRISIS drawn from the English economic mass-media discourse and the BNC of the two historical periods corresponding to the Great Depression of 1929-30es and the Great Recession of 2007-2010, mainly The Economist, The Financial Times, The New York Times (1929-1933 and 2007-2010). The $19^{\text {th }}$ century material is restricted to lexicographic data due to the difficulties of on-line accessing the media of this period.

As an algorithm, I suggest a four-stage analysis meant to define:

1) the semantic space of the concept in different periods;

2) the concept diachronically stable and variable lexical-semantic properties;

3 ) the range of conceptual metaphors of ECONOMIC CRISIS in the $20^{\text {th }}$ $21^{\text {st }}$ centuries;

4) the type of the concept evolution.

Concepts are meaningful units. The semantic properties of ECONOMIC CRISIS are singled out, first of all, as a result of analysis of lexical meanings. As Langacker (1987, p. 98) points out, "there should not be any difference in kind between conceptual structure and semantic structure; there is only a terminological distinction, the former being general the latter specifically linguistic". To reveal the relation between semantic and conceptual properties I built up a model of the concept in terms of Fillmore's frame semantics and use the elaboration of this theory in the "semantics of lingual networks" methodology developed by Zhabotynska (2010).

\section{Metaphors of ECONOMIC CRISIS in the $19^{\text {th }}$ and $21^{\text {st }}$ centuries: data and preliminary results}

The structure of the concept is much more complicated and more varied than the lexical meaning of words - its nominations. According to the Business dictionary definition, economic crisis is "a situation in which the economy of a country experiences a sudden downturn brought on by a financial crisis". So the name of the concept is terminological by nature. Its 
content is shaped by the meanings of the key lexeme "crisis" and a modifying adjective "economic".

According to dictionaries, "crisis" is a word with 12 lexical meanings which can be organized into the conceptual model of polysemy by a limited set of propositional schemas (classification, causation, likeness). Zhabotynska (2010, p. 75) argues that "such conceptual models, defined as ontologies, are multidimensional 'networks-in-the-networks' structures. At each dimension, the respective conceptual network is structured by a limited set of iterative propositions (propositional schemas) that belong to the five basic frames - the Thing, Action, Possession, Identification, and Comparison frames". These schemas organize the structure of ECONOMIC CRISIS through related concepts profiled within three overlapping domains and their subdomains which vary historically.

In the $19^{\text {th }}$ century, the model comprised two domains: ECONOMIC DECLINE (diminish, limit) and UNSTABLE SITUATION (with two subdomains: SHORTAGE - debt, deficit, and ANXIETY - panic, trouble). This is the period when crises are mainly local and short, the longest of them, 1873-1896 "long depression", does not exceed two decades and its actual scope is questioned by scholars.

In the $20^{\text {th }}$ century, when the Great Depression of the 1930-es covered the bigger part of America, Europe, and Asia, the conceptual space of ECONOMIC CRISIS expanded. The concept structure included two domains: ECONOMIC DECLINE (divided into two subdomains: CHANGE - recession, depression, decline, CULMINATION - dramatic, extreme, peak), and UNSTABLE SITUATION (already existing subdomains SHORTAGE and ANXIETY were supplemented by MALFUNCTION - collapse, crash, disaster, distress, failure, HARDSHIP - dilemma, difficulty, and DANGER - threat, menace, risk, jeopardy).

In the period of the $21^{\text {st }}$ century Global Financial crisis, the concept of ECONOMIC CRISIS suffers further transforms: the domain UNSTABLE SITUATION adds one more subdomain DISORDER (mess, turmoil); a new domain appears - TURNING POINT (subdomains LANDMARK - the Rubicon, milestone, crunch time, and ACCIDENT - calamity, mischance, catastrophe). Thus, the concept ECONOMIC CRISIS becomes a three domain conceptual structure as a result from the operation of prominence. 
Theorists question the ambivalent nature and semantic ambiguity of crisis: is it an event or a process? Within the former approach, crisis is a break of the course of events, within the latter, it is further subdivided into stages from a prodromal one to resolution (Fink, 2002; Haberler, 2001). This reveals the hybrid semantics of CRISIS as an event possessing signs of development.

ECONOMIC CRISIS is metaphorically conceptualized by a wide range of orientation, ontological and structural metaphors (Olijnyk, Shevchenko, 2016, p. 78 - 81). The hybrid event-and-process nature of the concept partially explains why metaphors of oriented movement represented by the conceptual metaphor ECONOMIC CRISIS IS MOVEMENT DOWN (severe declines in prices, loans moved downward, etc.) dominate in both periods and have the highest metaphorical potential. Such metaphors have varieties: ECONOMIC CRISIS IS LACK OF MOVEMENT (stagnation), ECONOMIC CRISIS IS MOVEMENT UP, e.g., the credit expansion brought to a halt, the prices highrocketed.

Among other historically stable metaphors, which are typical for the $20^{\text {th }}$ and $21^{\text {st }}$ mass-media discourse, the most frequent ones include source domains CONTAINER, EMERGENCY (STORM, EARTHQUAKE, DROUGHT, SHIPWRECK), MEDICINE, WAR, LIVING BEING (PERSON, ANIMAL):

- ECONOMIC CRISIS IS A CONTAINER (to be mires in economic crisis);

- ECONOMIC CRISIS IS AN EMERGENCY (financial postwar blizzard, key market dried up, recession of some magnitude, the good ship euro struck a reef);

- ECONOMIC CRISIS IS AN ILLNESS / MENTAL DISORDER (speculative fever, the global imbalances plagued the world, financial panic);

- ECONOMIC CRISIS IS A BATTLE/ AN EXPLOSION (economic hostilities, the bubble burst, the firm was the victim, financial bomb);

- ECONOMIC CRISIS IS A PERSON / AN ANIMAL (in the face of the crisis, birth pangs of the Great Depression, bear market, the credit crunch bites).

In the $21^{\text {st }}$ century, mass-media use new historically variable metaphors of ECONOMIC CRISIS, which appear as a result of cross-mapping between the target domain and source domains TECHNOLOGY and TERRORISM. They are 
specific for this epoch when man-made disasters are connected with nuclear energy or ecological threat, plane crashes, terrorist attacks, etc.:

- ECONOMIC CRISIS IS AN NPP / ECOLOGICAL ACCIDENT (a credit meltdown, global chain reaction, the toxicity of mortgage market);

- ECONOMIC CRISIS IS A CAR / PLANE CRASH (the crash in the financial sector, hard landing, the toxicity from the mortgage market).

In the last few years, the source domain MEDICINE of ECONOMIC CRISIS conceptual metaphors replenished with a new extension EPIDEMIC / PANDEMIC:

- ECONOMIC CRISIS IS AN EPIDEMIC (an epidemic of capital destruction).

To sum up this section, in terms of historical cognitive linguistics, concepts undergo transformations of the three main types: evolution, i.e. complication of the concept structure; involution or simplification of schematic presentation of the concept structure; and a mixed type development. In natural sciences, the gradual evolution of species is subdivided into cladogenesis and anagenesis. Borrowing these terms to linguistics, I use them to name the processes of historical complication of the concept structure with diachronic branching / splitting, which leads to forming new separate concepts (cladogenesis) and diachronic development without extinction (anagenesis). As the findings above demonstrate, the historical development of ECONOMIC CRISIS and its conceptual metaphors corresponds to the type of cladogenesis.

\section{Conclusion}

This paper views metaphoric conceptualization of ECONOMIC CRISIS in the $19^{\text {th }}-21^{\text {st }}$ centuries English mass-media discourse in terms of historical cognitive linguistics. It has revealed the diachronic transformation of the concept structure, which consists of historical constants - domains ECONOMIC DECLINE, UNSTABLE ECONOMIC SITUATION, and variables domain TURNING POINT and subdomains DISORDER, LANDMARK, ACCIDENT. Conceptual metaphors of ECONOMIC CRISIS result from cross-mapping of the source domains onto the target domain. The former comprise a historically constant and dominant in frequency source domain MOVEMENT (ECONOMIC CRISIS IS MOVEMENT DOWN) and variable source domains typical for the $21^{\text {st }}$ 
century: MAN-MADE DISASTER, TECHNOLOGICAL CRASH, EPIDEMIC, TERRORISM (ECONOMIC CRISIS IS NUCLEAR WINTER / PLANE CRASH / EPIDEMIC/ TERRORIST ATTACK). The paper has furthermore suggested a notion of evolutionary development borrowed from natural sciences to linguistics and defined the historical transformations of ECONOMIC CRISIS as cladogenesis, i.e. a complication of the concept structure and its splitting based on branching, which leads to forming separate concepts.

Finally, I firmly believe that historical cognitive linguistics will enrich our understanding of the intricate relationship between language, cognition and society. This new theoretical framework will open perspectives to further studies of concepts and categories in English and other languages.

\section{References}

Barcelona, A. (2006). Metonymy in meaning and form, with special attention to its role in lexical semantic change. In J.G. González, M.M Vázquez, P.R. Vaz, (Eds.). The historical linguistics - cognitive linguistics interface. Esp.: Universidad de Huelva, 19-57.

Bergson, H. (1911/2008). Creative evolution. New York: Holt and Company. Retrieved August 15, 2020 from https://www.gutenberg.org/files/26163/26163-h/26163-h.htm

Browse, S. (2013). (Mega-) metaphor in the text-worlds of economic crisis: towards a situated view of metaphor in discourse. (Doctoral dissertation). University of Sheffield.

BusinessDictionary.com. Retrieved May 5, 2020 from http://www.businessdictionary.com/definition/financial-crisis.html

Fink, S.L. (2002). Crisis management. Planning for the inevitable. An Authors Guild Backinprint.com edition Lincoln, USA: Universe Inc.

Fauconnier, G. (2006). Cognitive linguistics. In J. Wiley \& Sons (Eds).

Encyclopedia of Cognitive Science, 1-14. http://doi/org/10.1002/0470018860.s00214

Fauconnier, G., \& Turner, M. (2003). The way we think. New York: Basic Books.

Fortuine, R. (2000). The words of medicine: Sources, meanings, and delights. Springfield, Charles C Thomas Pub Ltd. 
Geeraerts, D., Kristiansen, G., and Peirsman, Y. (Eds.) (2010) Advances in cognitive sociolinguistics. Berlin: De Gruyter Mouton.

Guarddon-Anelo, C. (2006). A cognitive approach to the diachronic study of spatial preposition. In J.G. González, M.M Vázquez, P.R. Vaz, (Eds.). The historical linguistics - cognitive linguistics interface. Esp.: Universidad de Huelva, 147-165.

Haberler, G. von (2001). Prosperity and depression: A theoretical analysis of cyclical movements. Oregon: Pacific University Press.

Kövecses, Z. (2015) Levels of metaphor. Cognitive Linguistics, 28, N.2, 321-347. https://doi.org/10.1515/cog-2016-0052

Lakoff, G., and Johnson, M. (1980/2003). Metaphors we live by. Chicago:

University of Chicago Press.

Langacker, R.W. (1987). Foundations of Cognitive Grammar, 1:

Theoretical Prerequisites. Stanford, California: Stanford University Press.

Olijnyk, N., \& Shevchenko, I. (2016). Conceptualisation of ECONOMIC CRISIS in discourse: from the Great Depression to the Great Recession. Edvanced Education, 6, 76-81, https://doi.org/10.20535/2410-8286.78867

Oncins-Martínez, J.L. (2006) Notes on the metaphorical basis of sexual language in Early Modern English. In J.G. González, M.M Vázquez, P.R. Vaz, (Eds.). The historical linguistics - cognitive linguistics interface. Esp.: Universidad de Huelva, 205-224.

Pérez, R.G. (2006). Polysemy, metaphor and diachrony. A cross-linguistic study of body metaphors. In J.G. González, M.M Vázquez, P.R. Vaz, (Eds.). The historical linguistics - cognitive linguistics interface. (pp. 181-193). Esp.: Universidad de Huelva.

Robinson, A. (2010) Awesome insights into semantic variation. In D. Geeraerts, G. Kristiansen and Y. Peirsman, (Eds.). (2010) Advances in Cognitive Sociolinguistics.(pp. 85-109). Berlin: Mouton.

Shevchenko, I.S. (2015). Transformations of expressives through history in cognitive-communicative perspective. V.N. Karazin Univ. Messenger, 1155, 64-68. Retrieved from http://dspace.univer.kharkov.ua/handle/123456789/11086 
Silaški, N., \& Kilyeni, A. (2012) The global financial crisis and metaphors a contrastive analysis of English, Serbian and Romanian. Nasleđe. Vol. 21, 7-37. Retrieved August 15, 2020, from https://www.academia.edu

Stronach, I., Clarke, J., \& Frankham, J. (2014) Economic 'revelations' and the metaphors of the Meltdown: an educational deconstruction. British Educational Research Journal, 40 (2).

Winters, M.E. (2010). Introduction: On the emergence of diachronic cognitive linguistics. In M.E. Winters, H. Tissari, K. Allan (Eds.), Historical Cognitive Linguistics, 3-28. De Gruyter Mouton. http://doi/org/10.1515/9783110226447.3

Zhabotynska, S.A. (2010). Principles of building conceptual models for thesaurus dictionaries. Cognition, Communication, Discourse, 1, 75-92. Retrieved from https://sites.google.com/site/cognitiondiscourse/vypuskno12010/zabotinskaa-s-a

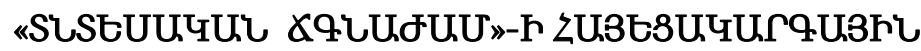

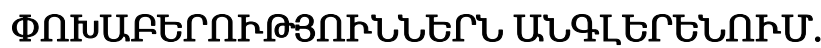 TUSUUXUนU2กาUЧUน UกSE8กhU}

\section{hphiur Clizkilun}

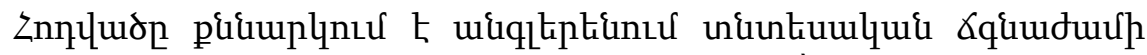

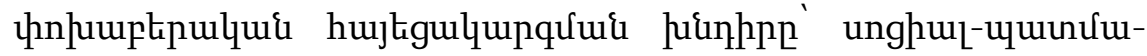

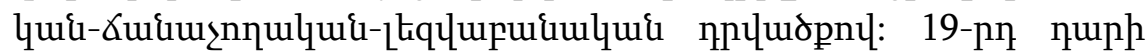

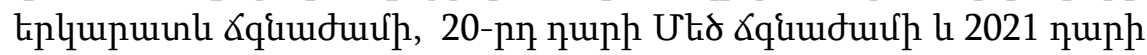

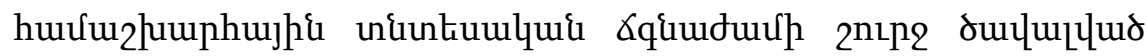

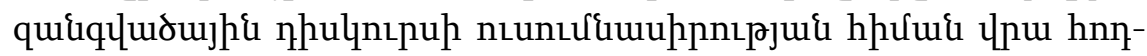

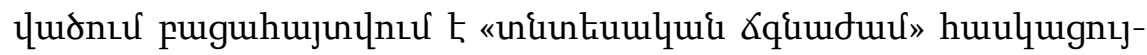

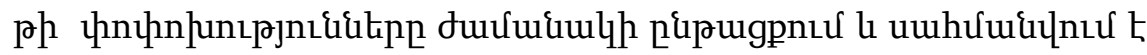

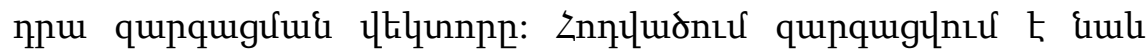

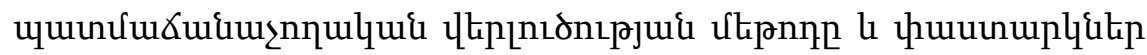

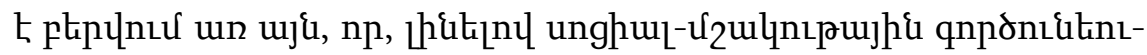

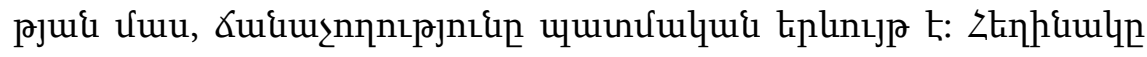

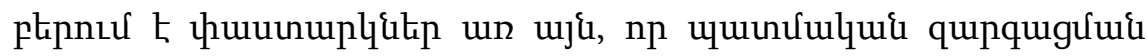

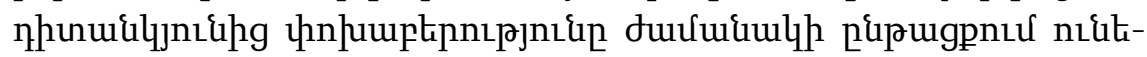

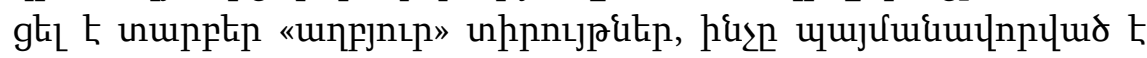

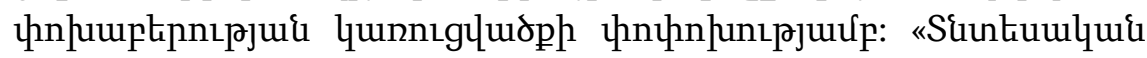




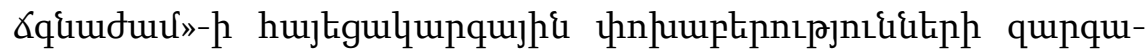

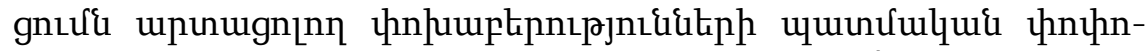

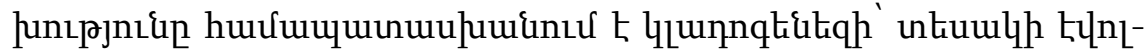

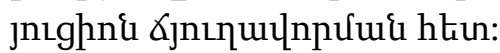

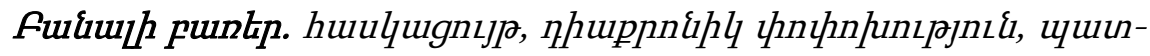

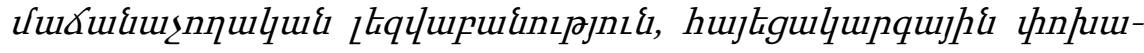
plipnıpjnık, hluinnqtiktiq: 